\title{
PROGRAMA BÁSICO DE GOBIERNO DE LA UNIDAD POPULAR: \\ CANDIDATURA PRESIDENCIAL DE SALVADOR ALLENDE ${ }^{1}$
}

\section{Unidad Popular}

Programa básico del gobierno de la Unidad Popular, aprobado por los Partidos Comunista, Socialista, Radical y Social Demócrata, el Movimiento de Acción Popular Unitaria (MAPU) y la Acción Popular Independiente, el 17 de diciembre de 1969 en Santiago de Chile.

El texto diagnostica la situación de crisis del sistema capitalista, manifestada en el estancamiento económico, la pobreza y desnutrición de la población. Acusa cómo los gobiernos anteriores han legislado a favor de unos pocos que controlan la economía, la prensa y el sistema político en general, sin considerar el bienestar común de la mayoría. Ante esta situación, la Unidad Popular plantea como única alternativa el término los monopolios y la oligarquía terrateniente para dar inicio al proceso de construcción del socialismo en Chile.

En el plano jurídico, este programa expresa la necesidad de contar con una nueva Constitución. En lo económico, destaca la necesidad de contar con un sistema fuerte y dispuesto para nacionalizar las riquezas básicas como la gran minería del cobre, hierro, salitre y otras que se encuentran en poder de capitales extranjeros y de monopolios internos y propone la aceleración, profundización y extensión de la reforma agraria como también la puesta en marcha de un sistema nacional de planificación económica.

En materia social, propone una política de remuneraciones capaz de determinar cuáles serían las cifras que efectivamente constituyan sueldos vitales y salarios mínimos en las diversas zonas del país. Propone unificar, mejorar y extender el sistema de seguridad social, asegurando la atención médica y dental, preventiva y curativa para todos. Determinación de fondos suficientes para llevar a cabo un amplio plan creación de viviendas.

1. Unidad Popular (1970). Programa básico de gobierno de la Unidad Popular: candidatura presidencial de Salvador Allende (Chile). Memoria Chilena, Biblioteca Nacional de Chile, pp. 1-32, 35-48. Disponible en: http://www.memoriachilena.gob.cl/602/w3-article-7738.html 
En materia de derechos ciudadanos, establece la plena capacidad civil de la mujer casada y la igual condición jurídica de todos los hijos habidos dentro y fuera del matrimonio, así como una adecuada legislación de divorcio con disolución del vínculo, con pleno resguardo de los derechos de la mujer y los hijos.

En materia cultural, reconoce la importancia y estimula la creación intelectual y artística. Promueve un sistema educacional democrático, único y planificado. Al respecto, presenta un amplio respaldo al proceso de la Reforma Universitaria, impulsando resueltamente su desarrollo como estrategia de democratización del saber y de eliminación de los privilegios de clase. 


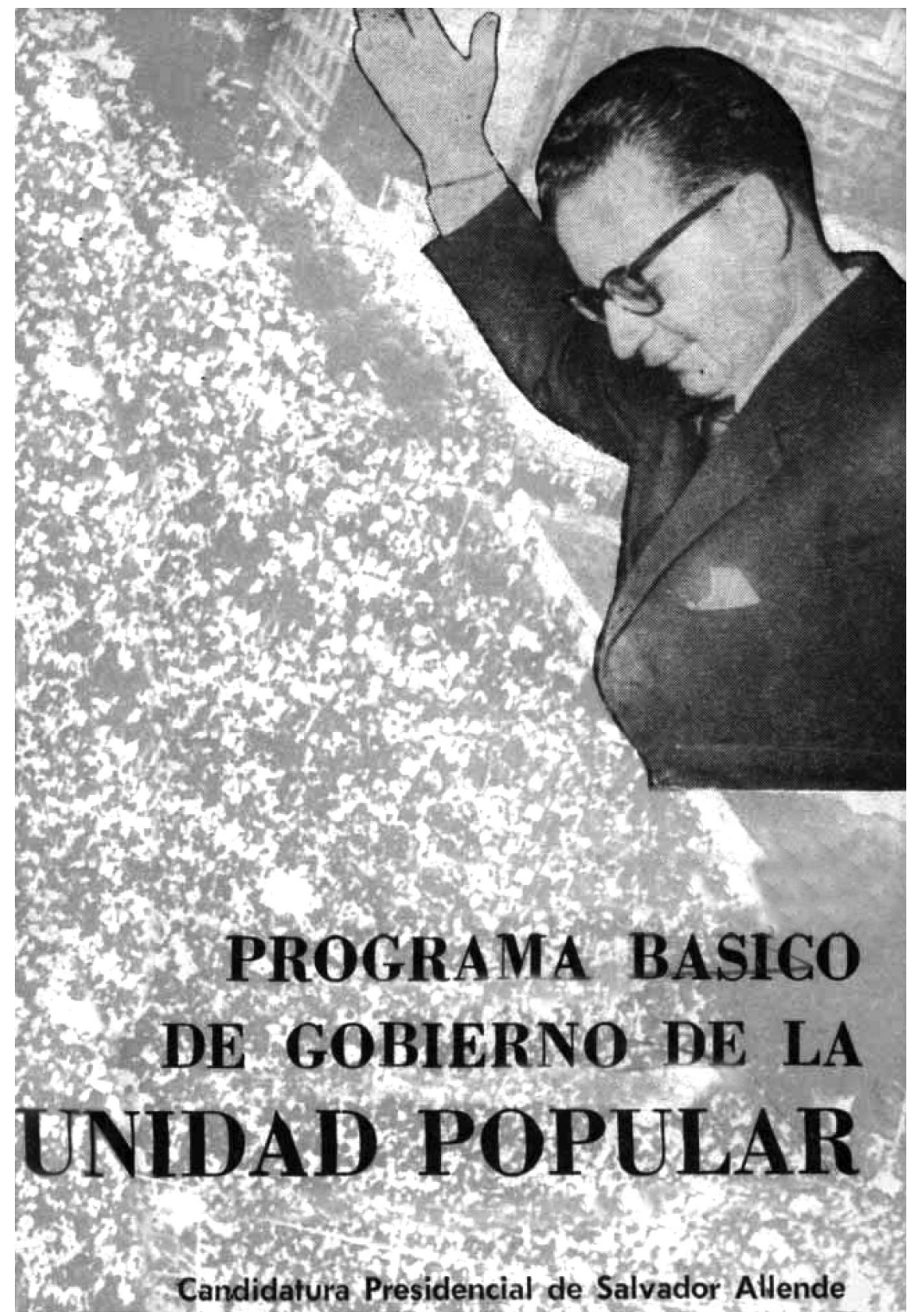




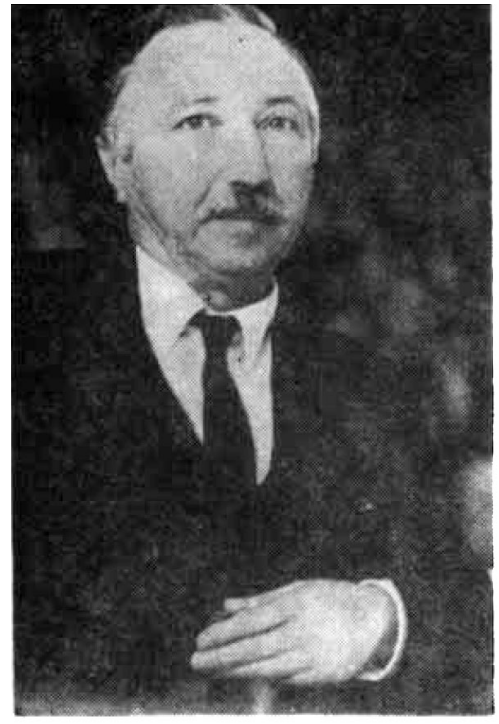

LUIS CORVALAN Secretario General del Partido Comunista

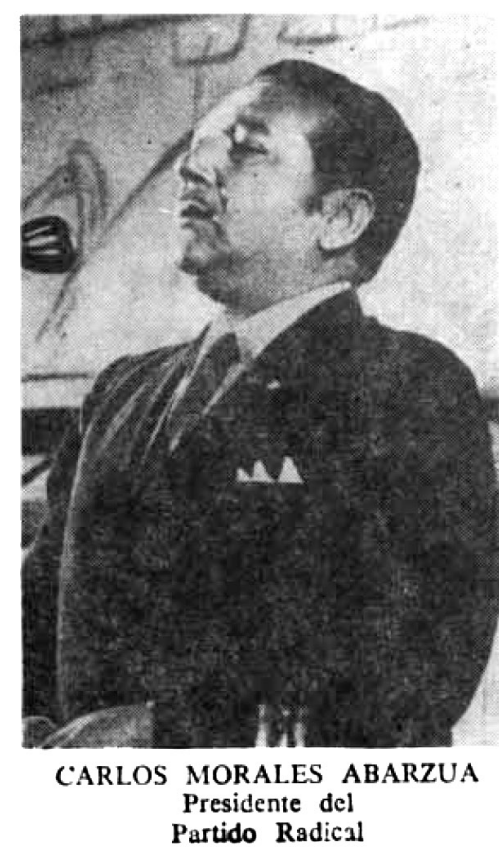

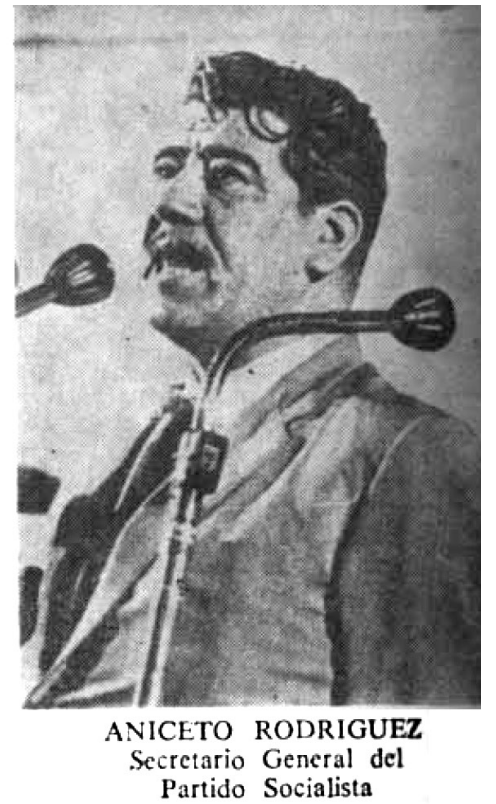

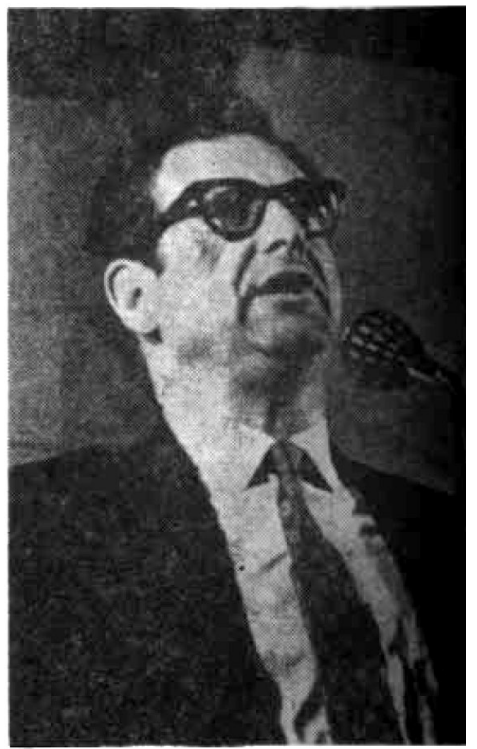

JACQUES CHONCHOI Presidente del Movimiento de Acción Popular Unituch 
BIBLIOTPCA NACIONAL

EL PROGRAMA BASICO

DE GOBIERNO DE LA

\section{UNIDAD POPULAR}

fue aprobado por los Partidos

Comunista, Socialista, Radical y

Social Demócrata, el Movimien-

to de Acción Popular Unitaria (MAPU) y la Acción Popular Independiente, el 17 de Diciembre de 1969 en Santiago de Chile. 


\section{Programa básico de gobierno de la Unidad Popular}

\section{INTRODUCGION}

Los partidos y movimientos que integran cl Comité Coordinador de la Unidad Popular, sin perjuicio de mantener cada cual su propia filosofía y sus propios perfiles políticos, coinciden plenamente en la caracterización de la realidad nacional expuesta a continuación y en las proposiciones programáticas que serán la base de nuestra acción común y que entregamos a consideración del pueblo.

1 Chile vive una crisis profunda que se manifiesta en el estancamiento económico y social, en la pobreza generalizada $\mathrm{y}$ en las postergaciones de todo orden que sufren los obreros, campesinos y demás capas explotadas, asi como en las crecientes dificultades que enfrentan empleados, profesionales, empresarios pequeños y medianos y en las minimas oportunidades de que disponen la mujer y la juventud.

Los problemas en Chile se pueden resolver. Nuestro pais cuenta con grandes riquezas como el cobre y otros minerales, un gran potencial hidroeléctrico, vastas extensiones de bosques, un largo litoral rico en especies marinas, una superficie agricola más que sufi- 
ciente, etc., cuenta, además, con la voluntad de trabajo y progreso de los chilenos, junto con su capacidad técnica y profesional. ¿Qué es entonces lo que ha fallado?

Lo que ha fracasado en Chile es un sistema que no corresponde a las necesidades de nuestro tiempo. Chile es un pais capitalista, dependiente del imperialismo, dominado por sectores de la burguesía estructuralmente ligados al capital extranjero, que no pueden resolver los problemas fundamentales del pais, los que se derivan precisamente de sus privilegios de clase a los que jamás renunciarán voluntariamente.

Más aún, como consecuencia misma del desarrollo del capitalismo mundial, la entrega de la burguesía monopolista nacional al imperialismo aumenta progresivamente, se acentúa cada vez más en su, dependencia, su papel de socio menor del capital extranjero.

Para unos pocos, vender a diario un pedazo de Chile es un gran negocio. Decidir por los demás es lo que hacen todos los días.

Para la gran mayoría en cambio vender a diario su esfuerzo, su inteligencia y su trabajo es un pésimo negocio, y decidir sobre su propio destino es un derecho del cual, en gran medida, aún están privados.

2 En Chile las recetas "reformistas" y "desarrollistas" que impulsó la Alianza para el Progreso e hizo suyas el gobierno de Frei no han logrado alterar nada importante. En lo fundamental ha sido un nuevo gobierno de la burguesia al servicio del capttalismo nacional y extranjero, cuyos débiles intentos de cambio social naufragaron sin pena ni gloria entre s] estancamiento econo mico, la carestía y la represión violenta contra el pueblo. Con esto se ha demostrado una vez más que el reformismo es incapaz de ro solver los problemas del puetlo. 
3 El desarrollo del capitalismo monopolista, niega la ampliación de la democracia y exacerba la violencia antipopular.

El aumento del nivel de lucha del pueblo, a medida que fracasa el reformismo, endurece la posición de los sectores más reaccionarios de las clases dominantes que, en último término, no tienen otro recurso que la fuerza.

Las formas brutales de la violencia del Estado actual, tales $\times$ mo las acciones del Grupo Móvil, el ap Jde campesinos y estudiantes, las $\mathrm{m} r$.1zas de pobladores $\mathrm{y}$ mineros, son inseparables de otras no menos brutales que afectan a todos los chilenos.

Porque violencia es, que junto a quienes poseen viviendas de lujo, una parte importante de la población habite en viviendas insalubres y otros no dispongan siquiera de un sitio; violencia es que mientras algunos botan la comida, otros no tengan cómo alimentarse.

4 La explotación imperialista de las economias atrasadas se efectúa de muchas maneras: a través de las inversiones en la minería (cobre, hierro, etc.), y en la actividad industrial, bancaria y comercial; mediante el control tecnológico que nos obliga a pagar altísimas sumas en equipos, licencias y patentes; de los préstamos norteamericanos en condiciones usurarias que nos imponen gastar en Estados Unidos y con la obligación adicional de transportar en barcos norteamericanos los productos comprados, etc.

Para muestra un solo dato. Desde 1952 hasta hoy, los norteamericanos invirtieron en América Latina 7 mil 473 millones de dólares y se llevarco 16 mil millones de dólares.

De Chile el imperialismo ha arrancado cuantiosos recursos equivalentes al doble del 
capital instalado en nuestro país, formado a lo largo de toda su historia.

Los monopolios norteamericanos, con la complicidad de los gobiernos burgueses, han logrado apoderarse de casi todo nuestro cobre, hierro y salitre. Controian el comercio exterior y dictan la política económica por intermedio del Fondo Monetario Internacional y otros organismos. Dominan importantes ramas industriales y de servicios; gozan de estatutos de privilegios, mientras imponen la devaluación monetaria, la reducción de salarios y sueldos y distorsionan la actividad agricola por la vía de los excedentes agropecuarios.

Intervienen también en la educación, la cultura y los medios de comunicación. Valiéndose de convenios militares y políticos tratan de penetrar las FF. AA.

Las clases dominantes. cómplices de esta situación e incapaces de valerse por ellas mismas, han intensificado en los últimos diez años el endeudamiento de Chile cop el extranjero.

Dijeron que los préstamos y compromisos con los banqueros internacionales podrian producir un mayor desarrollo económico. Pero lo único que lograron es que hoy dia Chile tenga el record de ser uno de los países más endeudados de la tierra en proporción a sus habitantes.

5 En Chile se gobierna y se legisla a favor de unos pocos, de los grandes capjtalistas y sus secuaces, de las compañías que dominan nuestra economia, de los latifundis. tas cuyo poder permanece casi intacto.

A los dueños del capital les interesa ganar siempre más dinero y no satisfacer las necesidades del pueblo chileno. Si producir e importar automóviles de alto precio, por ejemplo, es un buen negocio, se desvian hacia ese 
rubro valiosos recursos de nuestra economía, sin tener en cuenta que sólo un porcentaje ínfimo de chilenos están en condiciones de adquirirlos y que hay necesidades mucho más urgentes que atender, desde luego, en este mismo rubro, la de mejorar la locomoción colectiva, dotar de maquinaria a la agricultura, etc.

El grupo de empresarios que controla la economía, la prensa y otros medios de comunicación; el sistema político, y que amenaza al Estado cuando éste insinúa intervenir o se niega a favorecerlos, les cuesta muy caro a todos los chilenos.

Para que ellos se dignen seguir "trabajando", pues sólo ellos pueden darse el lujo de poder trabajar o no, es preciso:

- darles toda clase de ayuda. Los grandes empresarios estrujan al Estado bajo la amenaza que no habrá inversión privada si las ayudas y garantías que piden no se les otorgan;

- permitirles producir lo que ellos quieran con el dinero de todos los chilenos, en lugar de elaborar lo que necesita la gran mayoría del país;

- dejarlos llevarse las ganancias que obtienen a sus cuentas bancarias en el extranjero;

- dejarlos despedir obreros si éstos piden mejores salarios;

- permitirles manipular la distribución de alimentos, acapararlos para provocar escasez y de esta manera subir los precios a fin de continuar enriqueciéndose a costa del pueblo.

Mientras tanto, buena parte de los que efectivamente producen experimentan una difícil situación:

- Medio millón de familias carecen de viviendas y otras tantas o más viven en pési- 
mas condiciones en cuanto a alcantarillado, agua potable, luz, salubridad.

- La necesidad de la población en materia de educación y salud son insuficientemente atendidas.

- Más de la mitad de los trabajadores chilenos reciben remuneraciones insuficientes para cubrir sus necesidades vitales minimas. La desocupación y el trabajo inestable se sufre en cada familia. Para innumerables jóvenes la posibilidad de empleo se presenta muy dificil e incierta.

El capital imperialista y un grupo de privilegiados que no pasa del $10 \%$ de la población, acaparan la mitad de la renta nacional. Esto significa que de cada cien escudos que los chilenos producen, 50 van a parar a los bolsillos de 10 oligarcas y los otros 50 deben repartirse entre 90 chilenos, del pueblo y de la clase media.

6 El alza del costo de la vida es un infierno en los hogares del pueblo y, en especial, para la dueña de casa. En Ios últimos 10 años, según datos oficiales, el costo de la vida ha subido casi en un mil por ciento.

Esto significa que todos los dias se les roba una parte de su salario o de su sueldo a los chilenos que viven de su trabajo. Igual como le ocurre a los jubilados y pensionados, al trabajador independiente, al artesano, al pequeño productor, cuyas exiguas rentas son recortadas a diario por la inflación.

Alessandri y Frei aseguraron que pondrian término a la inflación. Los resultados están a la vista. Los hechos demuestran que lo inflación en Chile obedece a causas de fondo relacionadas con la estructura capitalista de nuestra sociedad y no con las alzas de remuneraciones como han pretendido hacer creer los sucesivos gobiernos para justificar 
la mantención del sistema y recortar los ingresos de los trabajadores. El gran capitalista, en cambio, se defiende de la inflación y más aún se beneficia con ella. Sus propiedades y capitales se valorizan, sus contratos de construcción con el Fisco se reajustan, y los precios de sus productos suben llevando siempre la delantera a las alzas de remuneraciones.

7 Un alto número de chilenos están mal alimentados. Según estadísticas oficiales, el $50 \%$ de los menores de 15 años de edad están desnutridos. La desnutrición afecta su crecimiento y limita su capacidad de aprender, de instruirse.

Esto demuestra que la economía en general y el sistema agrícola en particular, son incapaces de alimentar a los chilenos, pese a que Chile podría sustentar ahora mismo una población de 30 millones de personas, el triple de la población actual.

Por el contrario, debemos importar cada año centenares de miles de dólares en alimentos de origen agropecuario.

El latifundio es el gran culpable de los problemas alimentarios de todos los chilenos y responsable de la situación de atraso y miseria que caracteriza al campo chileno. Los indices de mortalidad infantil y adulta, de analfabetismo, de falta de viviendas, de insalubridad son, en las zonas rurales, marcadamente superiores a'los de las ciudades. Estos problemas no los ha resuelto la insuficiente Reforma Agraria del gobierno democratacristiano. Sólo la lucha del campesinado con el apoyo de todo el pueblo puede resolverlos. El actual desarrollo de sus combates por la tierra y la liquidación del latifundio abre nuevas perspectivas al movimiento popular chileno. 
8 El crecimiento de nuestra economía es mínimo. En los últimos lustros hemos crecido, en promedio, apenas a razón de un $2 \%$ anual por persona; y desde 1967 no hemos crecido, más bien hemos retrocedido, según las cifras del propio Gobierno (ODEPLAN). Esto quiere decir que en 1966 cada chileno tenía una mayor cantidad de bienes de la que tiene hoy. Ello explica que la mayoría esté disconforme y busque una alternativa para nuestro país.

- La única alternativa verdaderamente popular y, por lo tanto, la tarea fundamental que el Gobierno del Pueblo tiene ante sí, es terminar con el dominio de los imperialistas, de los monopolios, de la oligarquia terrateniente e iniciar la construcción del socialismo en Chile.

\section{LA UNIDAD Y LA ACGION del PUeblo organizado}

El crecimiento de las fuerzas trabajadoras en cuanto a su número, su organización, su lucha y la conciencia de su poder, refuerzan y propagan la voluntad de cambios profundos, la crítica del orden establecido y el choque con sus estructuras. En nuestro pais son más de tres millones de trabajadores, cuyas fuerzas productivas y su enorme capacidad constructiva, no podrán sin embargo liberarse dentro del actual sistema que sólo puede explotarles y someterles.

Estas fuerzas, junto a todo el pueblo, movilizando a todos aquellos que no están comprometidos con el poder de los intereses re accionarios, nacionales y extranjeros, o sea. mediante la acción unitaria y combativa de la inmensa mayoria de los chilenos, podrán romper las actuales estructuras y avanzär en la tarea de su liberación. 
La unidad popular se hace para eso.

Los imperialistas y las clases dominantes del país combatirán la unidad popular y tratarán de engañar una vez más al pueblo. Dirán que la libertad está en peligro, que la violencia se adueñará del país, etc. Pero las masas populares creen cada vez menos en estas mentiras. Diariamente crece su movilización social que hoy se ve reforzada $y$ alentada por la unificación de las fuerzas de izquierda.

Para estimular y orientar la movilización del pueblo de Chile hacia la conquista del poder. constituiremos por todas partes los Comités de la Unidad Popular, articulados en cada fábrica, fundo, población, oficina o escuela por los militantes de los movimientos $\mathrm{y}$ de los partidos de izquierda e integrados por esa multitud de chilenos que se definen por cambios fundamentales.

Los Comités de Unidad Popular no sólo serán organismos electorales. Serán intérpretes y combatientes de las reivindicaciones inmediatas de las masas y, sobre todo, se prepararán para ejercer el Poder Popular.

Asi, pues, este nuevo poder que Chile necesita debe empezar a gestarse desde ya, donde quiera que el pueblo se organice para luchar por sus problemas especificos y donde quiera que se desarrolle la conciencia de la necesidad de ejercerlo.

Este sistema de trabajo común será un método permanente y dinámico de desarrollo del Programa, una escuela activa para las masas y una forma concreta de profundizar el contenido politico de la Unidad Popular en todos sus niveles.

En un momento dado de la campaña los contenidos esenciales de este Programa, enriquecidos por la discusión y el aporte del pueblo y una serie de medidas inmediatas de gobierno, serán señaladas en un Acta del 
Pueblo que se constituirá para el nuevo Gobierno Popular y el Frente que lo sustenta, en un mandato irrenunciable.

Apoyar al candidato de la Unidad Popular no significa, por tanto, sólo votar por un hombre, sino también pronunciarse en favor del reemplazo urgente de la actual sociedad que se asienta en el dominio de los grandes capitalistas nacionales y extranjeros.

\section{EL PROGRAMA}

EI Poder Popular
Las transformaciones revolucionarias que el país necesita sólo podrán realizarse si el pueblo chileno toma en sus manos el poder $\mathrm{y}$ lo ejerce real y efectivamente.

El pueblo de Chile ha conquistado, a través de. un largo proceso de lucha, determinadas libertades y garantias democráticas, por cuya continuidad debe mantenerse en actitud de alerta y combatir sin tregua. Pero el poder mismo le es ajeno.

Las fuerzas populares y revolucionarias no se han unido para luchar por la simple sustitución de un Presidente de la República por otro, ni para reemplazar a un partido por ótros en el Gobierno, sino para llevar a cabo los cambios de fondo aue la situación nacional exige sobre la base del traspaso del poder. de los antiguos grupos dominantes a los trabajadores, al campesinado y sectores progresistas de las capas medias de la ciudac y del campo.

El triunfo popular abrirá paso así a régimen político más democrático de la historia del país.

En materia de estructura política el Gobierno Popular tiene la doble tarea de:

- preservar, hacer más efectivos y profundos los derechos democráticos y las conquistas de los trabajadores; y 
La profundización de la democracia $y$ las conquistas de los trabajadores
- transformar las actuales instituciones para instaurar un nuevo Estado donde los trabajadores y el pueblo tengan el real ejercicio del poder.

El Gobierno Popular garantizará el ejercicio de los derechos democráticos y respetará las garantías individuales y sociales de todo el pueblo. La libertad de conciencia, de palabra, de prensa y de reunión, la inviolabilidad del domicilio y los derechos de sindicalización y de organización regirán efectivamente sin las cortapisas con que los limitan actualmente las clases dominantes.

Para que esto sea efectivo, las organizaciones sindicales y sociales de los obreros, empleados, campesinos, pobladores, dueñas de casa, estudiantes, profesionales, intelectuales, artesanos, pequeños y medianos empresarios y demás sectores de trabajadores se. rán llamadas a intervenir en el rango que les corresponda en las decisiones de los órganos de poder. Por ejemplo, en las instituciones de previsión y de seguridad social, estableceremos la administración por sus propios imponentes, asegurando a ellos la elección democrática y en votación secreta de sus consejos directivos. Respecto de las empresas del sector público, sus consejos directivos y sus comités de producción deben contar con mandatarios directos de sus obreros y empleados.

En los organismos habitacionales correspondientes a su jurisdicción y nivel, las Juntas de Vecinos y demás organizaciones de pobladores dispondrán de mecanismos para fiscalizar sus operaciones e intervenir en múltiples aspectos de su funcionamiento. Pero, no se trata únicamente de estos ejemplos, sino de una nueva concepción en que el pueblo adquiere una intervención real $\mathbf{y}$ eficaz en los organismos del Estado. 
Asimismo, el Gobierno Popular garantizará el derecho de los trabajadores al empleo y a la huslga y de todo el pueblo a la educación y a la cultura, con pleno respeto de todas las ideas y de las creencias religiosas, garantizando el ejercicio de su culto.

Se extenderán todos los derechos y garantias democráticas entregando a las organizaciones sociales los medios reales para ejercerlos y creando los mecanismos que les permitan actuar en los diferentes niveles del aparato del Estado.

El Gobierno Popular asentará esencialmente su fuerza y su autoridad en el apoyo que le brinde el pueblo organizado. Esta es nuestra concepción de gobierno fuerte, opuesta por tanto a la que acuñan la oligarquía y el imperialismo que identifican la autoridad con la coerción ejercida contra el pueblo.

E1 Gobierno Popular scrá pluripartidista. Estará integrado por todos los partidos, movimientos y corrientes revolucionarias. Será así un ejecutivo verdaderamente democrático, representativo y cohesionado.

El Gobierno Popular respetará los derechos de la oposición que se ejerza dentro de los marcos legales.

El Gobicrno Popular iniciará de inmediato una real descentralización administrativa, conjugada con una planificación democratica $y$ eficiente que elimine el centralismo burocrático y 10 reemplace por la coor dinación de todos los organismos estatales.

Se modernizará la estructura de las municipalidades reconociéndoles la autoridad que les corresponde de acuerdo a los planes de coordinación de todo el Estado. Se tenderá a transformarlas en los órganos locales de la nueva organización politica, dotándolas de financiamiento y atribuciones adecur das, a fin de que puedan atender, en inter 
acción con las Juntas de Vecinos y coordinadas entre sí, los problemas de interés local de sus comunas y de sus habitantes. Deben entrar en funciones con este mismo propósito las Asambleas Provinciales.

La policía debe ser reorganizada a fin de que no pueda volver a emplearse como organismo de represión contra el pueblo y cumpla, en cambio, con el objetivo de defender a la población de las acciones antisociales. Se humanizará el procedimiento policial de manera de garantizar efectivamente el pleno respeto a la dignidad y a la integridad física del ser humano. El régimen carcelario, que constituye una de las peores lacras del actual sistema, debe ser transformado de raíz, con vista a la regeneración y recuperación de los que hayan delinquido.

\section{UN NUEVO ORDEN INSTITUGIONAL; EL ESTADO POPULAR}

A través de un proceso de democratización en todos los niveles y de una movilización organizada de las masas se construirá desde la base la nueva estructura del poder.

Una nueva Constitución Política institucionalizará la incorporación masiva del pueblo al poder estatal.

Se creará una organización única del Estado estructurada a nivel nacional, regional y local que tendrá a la Asamblea del Pueblo como órgano superior de poder.

La Asamblea del Pueblo será la Cámara Unica que expresará nacionalmente la soberania popular. En ella confluirán y se manifestarán las diversas corrientes de opinión.

Este sistema permitirá suprimir de raíz los vicios de que han adolecido en Chile tanto el presidencialismo dictatorial, como el parlamentarismo corrompido. 
Normas específicas determinarán y coordinarán las atribuciones y responsabilidades del Presidente de la República, ministros, Asamblea del Pueblo, organismos regionales y locales de poder y partidos políticos con el fin de asegurar la operatividad legislativa, la eficiencia del gobierno y, sobre todo, el respeto a la voluntad mayoritaria.

A fin de establecer la debida armonia entre los poderes que emanan de la voluntad popular y de que ésta pueda expresarse de un modo coherente, todas las elecciones se efectuarán en un proceso conjunto dentro de un mismo lapso de tiempo.

La generación de todo organismo de representación popular deberá realizarse por sufragio universal, secreto y directo, de los hom. bres y mujeres mayores de 18 años, civiles y militares, alfabetos y analfabetos.

Los integrantes de la Asamblea del Pueblo y de todo organismo de representación popular estarán sujetos al control de los electores, mediante mecanismos de consulta que podrán revocar sus mandatos.

Se establecerá un riguroso sistema de incompatibilidades que conduzca al término del mandato o de la privación de su cargo cuando un diputado o un funcionario de altas responsabilidades se desempeñe como gestor de intereses privados.

Los instrumentos de la política económica y social del Estado constituirán un sistema nacional de planificación, tendrán carácter ejecutivo y su misión será dirigir, coordinar y racionalizar la acción del Estado. Los planes con que opere deberán ser aprobados por la Asamblea del Pueblo. Los organismos de los trabajadores tendrán una intervención fundamental en el sistema de planificación.

Los organismos regionales y locales de poder del Estado Popular ejercerán autoridad 
en el radio geográfico que les corresponda y tendrán facultades económicas, políticas y sociales. Podrán, además, entregar iniciativas y ejercer la crítica a los organismos superiores.

Sin embargo, el ejercicio de las facultades de los organismos regionales y locales deberá ajustarse a los marcos fijados por las leyes nacionales y por los planes generales de desarrollo económico y social.

En cada uno de los niveles del Estado Popular se integrarán las organizaciones sociales con atribuciones específicas. A ellas les corresponderá compartir responsabilidades y desarrollar iniciativas en sus respectivos radios de acción, así como el examen y solución de los problemas de su competencia. Estas atribuciones no implicarán limitación alguna a la plena independencia y autonomía de las organizaciones.

Desde el día mismo que asuma el mando, el Gobierno Popular abrirá canales a fin de que se exprese la influencia de los trabajadores y del pueblo, por intermedio de las organizaciones sociales, en la adopción de decisiones y en la fiscalización del funcionamiento de la administración estatal.

Estos serán pasos decisivos para la liquidación del centralismo burocrático que caracteriza al sistema de administración actual.

organización de la justicia
La organización y administración de la justicia debe estar basada en el principio de la autonomía, consagrada constitucionalmente y en una real independencia económica.

Concebimos la existencia de un Tribunal Supremo, cuyos componentes sean designados por la Asamblea del Pueblo sin otra limitación que la que emanen de la natural idoneidad de sus miembros. Este tribunal generará libremente los poderes internos, 
unipersonales o colegiados, del sistema judicial.

Entendemos que la nueva organización y administración de justicia devendrá en auxilio de las clases mayoritarias. Además será expedita y menos onerosa.

Para el Gobierno Popular una nueva concepción de la magistratura reemplazará a la actual, individualista y burguesa.

La Defensa Nacional

El Estado Popular prestará atención preferente a la preservación de la soberanía nacional, lo que concibe como un deber de todo el pueblo.

El Estado Popular mantendrá una actitud alerta frente a las amenazas a la integridad territorial y a la independencia del pais alentadas por el imperialismo y por sectores oligárquicos que se entronizan en países vecinos y que junto con reprimir a sus pueblos alientan afanes expansionistas y revanchistas.

Definirá una concepción moderna patriótica y popular de la soberanía del país basada en los siguientes criterios:

a) Afianzamiento del carácter nacional de todas las ramas de las Fuerzas Armadas. En este sentido rechazo de cualquier empleo de ellas para reprimir al pueblo o participar en acciones que interesen a potencias extrañas.

b) Formación técnica y abierta a todos los aportes de la ciencia militar moderna, y conforme a las conveniencias de Chile, de la independencia nacional, de la paz y de la amistad entre los pueblos.

c) Integración $\mathrm{y}$ aporte de las Fuerzas Armadas en diversos aspectos de la vida social. El Estado Popular se preocupará de posibilitar la contribución de las Fuerzas Armadas al desarrollo económico del país sin 
perjuicio de su labor esencialmente de defensa de la soberanía.

Sobre estas bases, es necesario asegurar a las Fuerzas Armadas los medios materiales y técnicos y un justo y democrático sistema de remuneraciones, promociones y jubilaciones que garanticen a oficiales, suboficiales, clases y tropas la seguridad económica durante su permanencia en las filas y en las condiciones de retiro y la posibilidad efectiva para todos de ascender atendiendo sólo a sus condiciones personales.

\section{LA CONSTRUGGION DE LA NUEVA EGONOMIA}

Las fuerzas populares unidas buscan como objetivo central de su política reemplazar la actual estructura económica, terminando con el poder del capital monopolista nacional y extranjero y del latifundio, para iniciar la construcción del socialismo.

En la nueva economía la planificación jugará un papel importantísimo. Sus órganos centrales estarán al más alto nivel administrativo; y sus decisiones, generadas democráticamente, tendrár carácter ejecutivo.

Area de propiedad
El proceso de transformación de nuestra economía se inicia con una política destinada a constituir una área estatal dominante, formada por las empresas que actualmente posee el Estado más las empresas que se expropien. Como primera medida se nacionalizarán aquellas riquezas básicas que, como la gran minería del cobre, hierro, salitre y otras, están en poder de capitales extranjeros y de los monopolios internos, Así, quedarán integrando este sector de actividades nacionalizadas las siguientes: 
1) La gran minería del cobre, salitre, yodo, hierro y carbón mineral;

2) El sistema financiero del país, en especial la banca privada y seguros;

3) El comercio exterior;

4) Las grandes empresas y monopolios de distribución;

5) Los monopolios industriales estratégi$\cos$;

6) En general, aquellas actividades que condicionan el desarrollo económico y social del pais, tales como la producción y distribución de energia eléctrica; el transporte ferroviario, aéreo y marítimo; las comunicaciones; la producción, refinación y đistribución del petróleo y sus derivados, incluido el gas licuado; la siderurgia, el cemento, la petroquímica y química pesada, la celulosa, el papel.

Todas estas expropiaciones se harán siempre con pleno resguardo del interés del pequeño accionista.

El área de propiedad privada
Esta área comprende aquellos sectores de la industria, la minería, la agricultura y los servicios en que permanece vigente la propiedad privada de los medios de producción.

Estas empresas en numero serán la ma. yoria. Asi por cjemplo en 1967, de las $\mathbf{3 0 . 5 0 0}$ industrias (incluyendo la industria artesa nal), sólo unas 150 controlaban monopólica mente todos los mercados, concentrando la ayuda del Estado, el crédito bancario y explotando al resto de los empresarios indus. triales del pais vendiénđoles cara la mate. ria prima y comprándoles baratos sus productos.

Las empresas que integran este sector serán beneficiadas con la planificación general de la economía nacional. El Estado procurará la asistencia financiera y técnica necesarias a las empresas de esta área, para 
Area mixla

Profundización $y$ extensión de la Reforma Agraria que puedan cumplir con la importante función que desempeñan en la economía nacional, atendido el número de las personas que trabajan en ellas, como el volumen de la producción que generan.

Además, se simplificarán los sistemas de patentes, aranceles aduaneros, contribuciones y tributos para estas empresas y se les asegurará una adecuada y justa comercialización de sus productos.

En estas empresas se deberán garantizar los derechos de obreros y empleados a salarios y condiciones de trabajo justos. El respeto de estos derechos será cautelado por el Estado y los trabajadores de la empresa respectiva.

Este sector será mixto porque se compondrá de empresas que combinen los capitales del Estado a los particulares.

Los préstamos o créditos concedidos por los organismos de fomento a las empresas de esta área podrán serlo en calidad de aportes para que el Estado sea socio y no acreedor. Lo mismo será válido para los ca. sos en que dichas empresas obtengan créditos con el aval o garantía del Estado o de sus instituciones.

La Reforma Agraria es concebida como un proceso simultáneo y complementario con las transformaciones generales que se desea promover en la estructura social, política y económica del país, de manera que su reali. zación es inseparable del resto de la política general. La experiencia ya existente en esta materia y los vacíos o inconsecuencias que de ella se desprenden, conducen a reformu. lar la política de distribución y organiza ción de la propiedad de la tierra en base a las siguientes directivas: 
1 Aceleración del proceso de Reforma Agraria expropiando los predios que excedan a la cabida máxima establecida, según las condiciones de las distintas zonas, incluso los frutales, vitivinícolas y forestales, sin que el dueño tenga derecho preferencial a elegir la reserva. La expropiación podrá incluir la totalidad o parte de los activos de los predios expropiados (maquinarias, herramientas, animales, etc.).

2 Incorporación inmediata al cultivo mal explotadas de propiedad estatal.

3 Las tierras expropiadas se organizarán preferentemente en formas cooperativas de propiedad. Los campesinos tendrán títulos de dominio que acrediten su propiedad sobre la casa y el huerto que se les asigne y sobre los derechos correspondientes en el predio indivisible de la cooperativa.

Cuando las condiciones lo aconsejen, se asignarán tierras en propiedad personal a los campesinos, impulsando la organización del trabajo y de la comercialización sobre bases de cooperación mutua.

También se destinarán tierras para crear empresas agricolas estatales con la tecnología moderna.

4. En casos calificados se asignarán tierras a los pequeños agricultores, arren. datarios, medieros y empleados agrícolas capacitados para el trabajo agropecuario.

5 Reorganización de la propiedad minifundiaria a través de formas progresi vamente cooperativas de trabajo agricola.

6 Incorporación de los pequeños y me- 
Polifica de desarrallo económico vicios de las cooperativas que operen en su área geográfica.

7 Defensa de la integridad y ampliación y asegurar la dirección democrática de las comunidades indígenas, amenazadas por la usurpación, y que al pueblo mapuche y demás indígenas se les asegure tierras suficientes y asistencia técnica y crediticia apropiadas.

La politica económica del Estado se llevará adelante a través del sistema nacional de planificación económica y de los mecanismos de control, orientación, crédito a la producción, asistencia técnica, política tributaria y de comercio exterior, como asimismo median. te la propia gestión del sector estatal de la economia. Tendrá como objetivos:

1 Resolver los problemas inmediatos de las grandes mayorías. Para esto se volcará la capacidad productiva del país de los artículos superfluos y caros destinados a satisfacer a los sectores de altos ingresos ha cia la producción de artículos de consumo popular, baratos y de buena calidad.

2 Garantizar ocupación a todos los chile. nos en edad de trabajar con un nivel de remuneraciones adecuado. Esto significará diseñar una política que genere un gran empleo proponiéndose el uso adecuado de los recursos del país y la adaptación de la tecnología a las exigencias del desarrollo na. cional.

3 Liberar a Chile de la subordinación al capital extranjero. Esto lleva a expropiar el capital imperialista, a realizar una política de un creciente autofinanciamiento 
de nuestras actividades, a fijar las condiciones en que opera el capital extranjero que no sea expropiado, a lograr una mayor independencia en la tecnología, el transporte externo, etc.

4 Asegurar un. crecimiento económico rápido y descentralizado que tienda a desarrollar al máximo las fuerzas productivas, procurando el óptimo aprovechamiento de los recursos humanos, naturales, financieros y técnicos disponibles a fin de incrementar la productividad del trabajo y de satisfacer tanto a las exigencias del desarrollo independiente de la economía, como a las necesidades y aspiraciones de la población tra. bajadora, compatibles con una vida digna y humana.

-5 Ejecutar una política de comercio exterior tendiente a desarrollar y diversificar nuestras exportaciones, abrir nuevos mercados, lograr una creciente independencia tecnológica y financiera y evitar las escandalosas devaluaciones de nuestra moneda.

6 Tomar todas las medidas conducentes a la estabilidad monetaria. La lucha contra la inflación se decide esencialmente con los cambios estructurales enunciados. Debe, además, incluir medidas que adecúen el flujo de circulante a las reales necesidades del mercado, controle y redistribuya el crédito y evite la usura en el comercio del dinero. Racionalice la distribución y el comercio. Estabilice los precios. Impida que la estructura de la demanda proveniente de las altas rentas incentive el alza de los precios.

La garantía del cumplimiento de estos objetivos reside en el control por el pueblo organizado del poder político y económico, 
expresado en el área estatal de la economía y en la planificación general de ésta. Es este poder popular el que asegurará el cumpli. miento de las tareas señaladas.

\section{TAREAS SOGIALES}

Las aspiraciones sociales del pueblo chileno son legitimas y posibles de satisfacer. Quiere, por ejemplo, viviendas dignas sin reajustes que esquilmen sus ingresos; es. cuelas y universidades' para sus hijos; salarios suficientes; que terminen de una vez las alzas de precios; trabajo estable; aten. ción médica oportuna; alumbrado público, alcantarillado, agua potable, calles y aceras pavimentadas; una previsión social sin pri. vilegios, justa y operante, sin pensiones de hambre; teléfonos, policías, jardines infan. tiles, canchas deportivas; turismo y balnea. rios populares.

La satisfacción de estos justos anhelos del pueblo -que en verdad constituyen dere. chos que la sociedad debe reconocerle - será preocupación preferente del Gobierno Popular.

Puntos básicos de esta acción de gobierno serán:

a) Definición de una política de remuneraciones, procediendo a crear de inmediato los organismos que con participación de los trabajadores, determinarán cifras que efectivamente constituyan sueldos vitales y salarios mínimos en las diversas zonas del pais.

Mientras subsista la inflación se proce. derá a establecer por ley reajustes automáticos, de acuerdo con el alza del costo de la vida. Estos operarán cada seis meses o cada vez que el costo de la vida supere un nivel de $5 \%$ de crecimiento.

En todos los organismos del Estado, y en 
primer lugar en los cargos de confianza del Ejecutivo, se limitarán los sueldos altos a una cifra compatible con la situación de nuestro país.

Se procederá en un plazo que será defi nido técnicamente, a establecer un sistema de sueldos y salarios mínimos de niveles iguales para trabajos iguales, cualquiera sea la empresa donde estos trabajos se realicen. Esta política se iniciará en el área estatal para irla extendiendo a toda la economía, sin perjuicio de las diferencias derivadas de pro. ductividades dispares en distintas empresas. Del mismo modo se eliminará toda discri. minación entre el hombre y la mujer o por edad en materia de sueldos y salarios.

b) Unificar, mejorar y extender el sistema de seguridad social, manteniendo todas las conquistas legitimas alcanzadas, eliminando los privilegios abusivos, la ineficiencia y el burocratismo, mejorando y hacien. do expedita la atención de los interesados, extendiendo el sistema previsional a los sectores de trabajadores que aún no la tienen, y entregando a los imponentes la administración de las Cajas de Previsión, las que fun. cionarán dentro de las normas de la planificación.

c) Asegurar la atención médica y dental, preventiva y curativa a todos los chilenos, financiada por el Estado, los patrones y las instituciones de previsión. Se incorporará la población a la tarea de proteger la salud pú. blica.

Los medicamentos, sobre la base de un es. tricto control de costos en los laboratorios y la racionalización de la producción, se en. tregarán en cantidad suficiente y a bajo precio.

d) Se destinarán fondos suficientes a fin de llevar a cabo un amplio plan de edifica ción de viviendas. Se desarrollará la indus- 
trialización de la construcción controlando sus precios, limitando el monto de las uti. lidades de las empresas privadas o mixtas que operan en este rubro. En situaciones de emergencia se asignarán terrenos a las familias que los necesiten, facilitándoles ayuda técnica y material para edificar sus viviendas.

El Gobierno Popular tendrá como objetivo de su política habitacional que cada fa. milia llegue a ser propietaria de una casa habitación. Se eliminará el sistema de dividendos reajustables. Las cuotas o rentas mensuales que deban pagar los adquirientes de viviendas $\mathrm{y}$ arrendatarios, respectivamente, no excederán, por regla general, del $10 \%$ del ingreso familiar.

Llevar adelante la remodelación de ciuda. des y barrios, con el criterio de impedir el lanzamiento de los grupos modestos a la periferia, garantizando los intereses del habitante del sector remodelado, como del pequeño empresario que allí labore, asegurando a los ocupantes su ubicación futura.

e) Se establecerá la plena capacidad civil de la mujer casada y la igual condición jurídica de todos los hijos habidos dentro o fuera del matrimonio así como una adecuada legislación de divorcio con disolución del vínculo, con pleno resguardo de los derechos de la mujer y los hijos.

f) La división legal entre obreros y em. pleados será suprimida, estableciendo para ambos la calidad común de trabajadores y extendiendo el derecho a sindicalizarse a todos aquellos que actualmente no lo tienen.

\section{CULTURA Y EDUCAGION}

Una cultura nueva para la sociedad
El procesc social que se abre con el triunfo del pueblo irá conformando una nueva cultura orientada a considerar el trabajo huma- 
no como el más alto valor, a expresar la voluntad de afirmación e irıdependencia nacional y a conformar una visión crítica de la realidad.

Las profundas transformaciones que se emprenderán requieren de un pueblo socialmente consciente y solidario, educado para ejercer y defender su poder politico, apto cientifica y técnicamente para desarrollar la economía de transición al socialismo $y$ abierto masivamente a la creación y goce de las más variadas manifestaciones del arte y del intelecto.

Si ya hoy la mayoría de los intelectuales y artistas luchan contra las deformaciones culturales propias de la sociedad capitalista y tratan de llevar los frutos de su creación a los trabajadores $y$ vincularse a su destino histórico, en la nueva sociedad tendrán un lugar de vanguardia para continuar con su acción. Porque la cultura nueva no se creará por decreto; ella surgirá de la lucha por la fraternidad contra el individualismo; por la valoración del trabajo humano contra su desprecio; por los valores nacionales contra la colonización cultural; por el acceso de las masas populares al arte, la literatura y los medios de comunicación contra su comercialización.

El nuevo Estado procurará la incorporación de las masas a la actividad intelectual y artistica, tanto a través de un sistema educacional radicalmente transformado, como a través del establecimiento de un sistema nacional de cultura popular. Una extensa red de Centros Locales de Cultura Popular impulsará la organización de las masas para ejercer su derecho a la cultura.

El sistema de cultura popular estimulará la creación artística y literaria y multiplicará los canales de relación entre artistas 0 es- 
Un sistema educacional democrático, único $v$ planificado

critores con un público infinitamente más vasto que el actual.

La acción del nuevo Gobierno se orientará a entregar las más amplias y mejores oportunidades educacionales.

En el cumplimiento de estos propósitos influirá el mejoramiento general de las condiciones de vida de los trabajadores y la consideración, en el nivel que corresponde, de las responsabilidades de los educadores. Además, se establecerá un Plan Nacional de Becas lo suficientemente extenso como para asegurar la incorporación y la continuidad escolar a todos los niños de Chile, especialmente a los hijos de la clase obrera y del campesinado.

Por otra parte, el nuevo Estado desarrollará un plan extraordinario de construcción de establecimentos escolares, apoyado en recursos nacionales y locales movilizados por los órganos básicos de poder. Se expropiarán las edificaciones suntuarias que se requieran para habilitar nuevos establecimientos escolares e internados. Por estos medios se tenderá a crear por lo menos una escuela unificada (básica y media). en cada comuna rural, en cada barrio y en cacia población de las ciudades de Chile.

Con el fin de atender a las necesidades de desarrollo propias de la edad preescolar y para posibilitar la incorporación cle la mujer al trabajo productivo. se extenderá rápidamente el sistema de salas-cuna $\mathrm{v}$ jardines infantiles, otorgando prioridad a los sectores más necesitados de nuestra sociedad. Por efecto de esta misma política, la niñez obrera y campesina estará más apta para ingresar y permanecer provechosamente en el sistema escolar regular.

Para hacer efectiva una nueva enseñanza 
se requiere la aplicación de métodos que pongan énfasis en una participación activa y crítica de los estudiantes en su enseñanza, en vez de la posición pasiva y receptiva que ahora deben mantener.

"Para liquidar rápidamente los déficit culturales y educacionales heredados del actual sistema, se llevará a cabo una amplia movilización popular destinada a eliminar a breve plazo el analfabetismo. a elevar los niveles de escolaridad de la población adulta.

La educación de adultos se organizará principalmente en función de los centrus laborales, hasta hacer posible el funcionamiento permanente de la educación general, tecnológica y social para los trabajadores.

La transformación del sistema educacional no será obra sólo de técnicos sino tarea estudiada, discutida, decidida y ejecutada por las organizaciones de maestros, trabajadores, estudiantes $\mathrm{y}$ padres y apoderados, dentro de los marcos generales de la planificación nacional. Internamente, el sistema escolar se planificará respetando los principios de unidad, continuidad, correlación y diversificación de la enseñanza.

En la dirección eiecutiva del aparato educacional habrá efectiva representación de las organizaciones sociales ya señaladas, integradas en Consejos Locales, Regionales y Nacional de Educación.

Con el objeto de hacer realidad la planifjcación de la erlucación y la escuela única, nacional y democrática, el nuevo Estado tomará bajo su responsabilidad los establecimientos privados, empezando por aquellos planteles que seleccionan su alumnado por razones de clase social, origen nacional o confesión religiosa. Esto se realizará integrando al sistema educacional el personal y otros medios de la educación privada. 
La Educación La educación física y las prácticas de to-

Fisica dos los deportes, desde los niveles básicos del sistema educacional y en todas las organizaciones sociales de jóvenes y adultos serán la preocupación constante y metódica del Gobierno Popular.

Democracia. autonomía $y$ orientación de la Universidad

El Gobierno de Unidad Popular prestará un amplio respaldo al proceso de la Reforma Universitaria e impulsará resueltamente su desarrollo. La culminación democrática de este proceso se traducirá en importantes aportes de las universidades al desarrollo revolucionario chileno. Por otra parte, la reorientación de las funciones académicas de docencia, investigación y extensión en función de los problemas nacionales será alentada por las realizaciones del Gobierno Popular.

Ei Estado asignará a las universidades recursos suficientes para asegurar el cumplimiento de sus funciones y su efectiva estatización y democratización. Consecuentemente, el gobierno universitario corresponderá a sus respectivas comunidades.

A medida que en el conjunto del sistema educacional se eliminen los privilegios de clases se hará posible el ingreso de los hijos de los trabajadores a la Universidad y permitirá también a los adultos, ya sea mediante becas especiales o a través de sistemas de estudio y trabajo simultáneo, ingresar a cursos de nivel superior.

Los medios de comunicación masiva
Estos medios de comunicación (radio, editoriales, televisión, prensa, cine), son fundamentales para ayudar a la formación de una nueva cultura y un hombre nuevo. Por eso se deberá imprimirles una orientación educativa y liberarlos de su carácter comercial, adoptando las medidas para que las organizaciones sociales dispongan de estos medios 
eliminando en ellos la presencia nefasta de los monopolios.

El sistema nacional de cultura popular se preocupará especialmente del desarrollo de la industria cinematográfica y de la preparación de programas especiales para los medios de comunicación masiva.

\section{POLITICA INTERNACIOHAL DEL GOBIERHO POPULAR}

\section{Objetivos}

La política internacional del Gobiemo Popular estará dirigida a:

Afirmar la plena autonomía política y económica de Chile.

Existirán relaciones con todos los paises del mundo, independientemente de su posición ideológica y política, sobre la base del respeto a la autodeterminación y a los intereses del pueblo de Chile.

Se establecerán vinculos de amistad y solidaridad con los pueblos independientes o colonizados, en especial aquellos que están desarrollando sus luchas de liberación e independencia.

Se promoverá un fuerte sentido latinoamericanista y antiimperialista por medio de una politica internacional de pueblos antes que de cancillerias.

La defensa decidida de la autodeterminación de los pueblos será impulsada por el nuevo Gobierno como condición básica de la convivencia internacional. En consecuencia, su políticá será vigilante y activa para defender el principio de no intervención y para rechazar todo intento de discriminación, presión, invasión o bloquec intentado por los países imperialistas.

Se reforzarán las relaciones, el intercambio y la amistad con los paises socialistas. 


\section{Pacto de la Unidad Popular}

El pueblo a la victoria

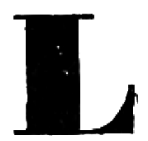

OS partidos y movimientos de izquierda han acordado dar a conocer al pueblo el presente pacto político de Gobierno y de la Unidad Popular, conscientes de que los objetivos programá-

ticos que se han trazado están decisivamente vinculados a un nuevo concepto de la conducción del pais, que el Gobierno Popular que vamos a conquistar se propone poner en practica.

El proceso politico chileno de los últimos años ha ido creando las condiciones necesarias para una mayor polarización $y$ definicion de las fuerzas en lucha. Ello se ha traducido en el campo de la Izquierda en posibilitar favorablemente valiosos esfuerzos unitarios que han culminado en la constitución del Comité Coordinador de la Unidad Popula:, en la concertación de un programa comin $y$ en la decisión de conducir al pueblo a la victoria para realizar un gobierno eficaz, cuya amplia base de sustentación la aportará plural e integradamente la totalidad de los partidos como movimientos y fuerzas sociales que han hecho posible la unidad del pueblo. 


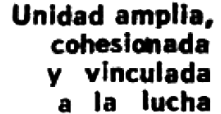

Unidos más allá de la elección presidencial

Clamor unitario del pueblo
La unidad forjada es amplia y a la vez cohesionada. En ella participan hombres y mujeres de diversas filosofias o creencias: marxistas, laicos, cristianos, independientes, etcétera. Está vinculada a la lucha del pueblo, de los estudiantes, de los sectores medios, y expresa los intereses de todas las fuerzas sociales ajenas al poder de los grandes capitalistas nacionales $\mathrm{y}$ extranjeros. Integrada por las fuerzas politicas de izquierda y abierta a todos los que están por cambios verdaderos, basa su acción en un programa claro sin ambigüedades, elaborado en $\mathrm{co}^{-}$ mún, y en un trabajo coordinado y de equipo, respaldado por la firme voluntad de superar las diferencias y todo aquello que divida o parcialice, excluyendo toda forma de hegemonías partidistas.

Por tanto, los partidos y movimientos integrantes del Comité Coordinador de la Unidad Popular libraran la batalla presidencial con el firme propósito de conquistar un gobierno que realice verdaderamente los cambios profundos que reclama con urgencia nuestro pais. Más allá de septiembre de 1970 , proseguirán unidos con la firme decisión de enirental juntos todas las etapas indispensables para liberal a Chile del imperialismo, la explotación y la miseria.

En definitiva, la Unidad Popular ha surgido como una unión politica consecuente y estable, que se irá reforzando cada día al participar en común en los múltiples combates del pueblo por la solución de sus problemas y la realización de los cambios revolucionarios.

Se concreta asi en nuestro país la posibilidad cierta de constituir un gobierno que responda al clamor unitario que viene desde la base misma del pueblo. La Unidad Popu- 
Será el

Gobierno del pueblo y no de un hombre

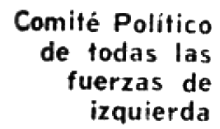

lar surge como una alternativa de poder, la única verdaderamente capaz de resolver los problemas de las grandes mayorias nacionales.

Chile vive como nunca en la indefinición, la incertidumbre y la confusión. Frente a ello creemos que es necesario ser muy claros y categóricos para decir lo que buscamos.

Hemos coincidido en la definición de una forma o concepción de gobierno orientada a garantizar el cumplimiento de los postulados programáticos comunes.

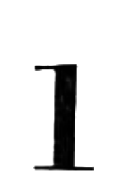

Declaramos enfáticamente que el candidato y los partidos y movimientos que lo apoyan harán un Gobierno del Pueblo - no de un hombre - dirigiendo al país sobre bases de integración y colaboración de las colectividades políticas populares, y las organizaciones sindicales y de masas, asumiendo cada cual su respectiva responsabilidad en los escalones correspondientes del Estado y la conducción del país. El Gobierno Popular actuará de acuerdo con la mayoría nacional. será pluripartidista y las decisiones esenciales conside rarán la opinión común de las fuerzas que lo generan e integran. No será, por tanto, un gobierno de un solo partido y mucho menos un gobierno personal. No elegiremos un monarca, sino un mandatario del pueblo. En los órganos de dirección del gobierno estarán representados todos los partidos y movimientos que lo generen.

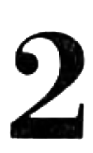

En el Gobierno de la Unidad Popular la acción del Presidente de la República y la de los partidos y movimientos que lo formen será coordinada a través de un Comité Político inte- 
grado por todas estas fuerzas. Tal comité operará de acuerdo con las orientaciones generales definidas por el programa común, y considerará con el Presidente de la República su ejecución, la operatividad de los planes de gobierno y en especial la marcha en la aplicación de las medidas económicas, sociales, de orden público y de política internacional, asi como la de racionalización, desburocratización y eficiencia de los servicios del Estado.

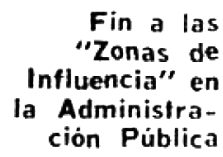

Gobierno

fuerte por su

base social
Las fuerzas populares declaran su decisión de evitar absolutamente la parcelación y el establecimiento de zonas de influencia en las diversas reparticiones de la Administración Pública.

En cada nivel de trabajo y en las esferas decisivas de la administración estatal estarán presentes todas las fuerzas que generen el Gobierno Popular, actuando conjuntamen be entre si y con las organizaciones sociales de los trabajadores y el pueblo interesadas en el área respectiva. Esta forma de funcionamiento garantizará la adecuada y oportuna atención a los problemas. la eficiencia de la administración y la prontitud en las decisio nes.

El Gobierno de la Unidad Popular será un gobierno fuerte. no en el sentido policial y represivo, sino por la solidez y definición de sus principios, su politica. su programa, por su amplia base social, por la coordinación constructiva de las fuerzas políticas que lo integran, por el apoyo resuelto del pueblo, que ejercerá el poder a través de sus partidos y de sus organizaciones sociales representativas en diversas instancias $y$ niveles. 
El fracaso det absolutismo en Chile

El engaño de la Derecha
Sólo un gobierno asi estructurado y con tal concepción de la autoridad está en condiciones de enfrentar y resolver los problemas de Chile.

En nuestro país han fracasado los gobiernos concebidos sobre la base de tener como único factor o centro la persona del Presidente de la República, como ser omnipontente y absolutista.

El gobierno personal se ha transformado siempre en la expresión del poder de los reaccionarios, en el vehículo de la politiquería, de los compromisos sin principios, de la repartición de prebendas como forma de pago de servicios electorales. Con ello la acción dispersa e improvisada, la desorganización y las contradicciones en las lineas de trabajo de las diversas ramas del Poder Ejecutivo se convierten en características de la conducta de gobierno con las funestas consecuencias conocidas y que el pais padece. A la sombra de tales criterios los centros de poder constituidos por el imperialismo y la oligarquía con su cohorte de gestores obtienen excepcionales tacilidades para influir en la orientación del Estado. Eș la experiencia de los gobiernos de los últimos sexenios, particularmente de Alessandri y Frei.

Denunciamos por ello el engaño de la propaganda del señor Alessandri y la Derecha, que pretenden hacer creer que los problemas de Chile se resolverían por la via de un gobierno unipersonal, el gobierno de un hombre solo, falsamente independiente, aparentemente situado por encima de todos los intereses, como si no tuviera compromisos con grupos y partidos y se hallare animado por el propósito de gobernar para todos los chilenos sin distinción de clases. 
Quién es realmenfe Alessandri

Tomic baila en la misma cuerda

La Unidad Popular no tiene nada que oculfar
E1 señor Alessandri expresa intereses económicos y de clase, está íntimamente unido a ellos, es su representante natural, así como está unido también a los intereses partidistas más reaccionarios del país.

En 1958 fue elegido Presidente por los partidos Conservador y Liberal y el suyo fue un gobierno de partidos. Ahora todo el mundo sabe que es el candidato del Partido Nacional y que gobernaría con él, si fuera elegido, puesto que sus ministros, altos funcionarios y otros colaboradores principales saldrían del Partido Nacional, de su esfera de influencia o de los gerentes de los grandes consorcios. $Y$ serian esta influencia, esta composición de clase, las que definirian las orientaciones de tal gobierno. Sobre esto nadie puede engañarse.

Tampoco puede embaucar al país el señor Tomic, que pretende, igualmente, bajo otra forma de personalismo, desligarse del fracaso del gobierno que ha servido y representa. Tras un verbalismo populista, que llega al mayor desenfreno demagógico, está el afán de ocultar la contradicción clara a los ojos del pucblo derivada de la falta de correspondencia entre lo que se dice y lo que se hace. Promete sustituir el capitalismo, pero es el candidato de un gobierno que lo ha afianzado. Hace críticas rotundas al sistema, como si el Gobierno y el partido que le apoyan no fueran los actuales administradores de ese sistema. La fuerza política con la que tendria que gobernar es la misma con la que ha go. bernado Frei $y$, sin embargo, quiere hace: creer que su gobierno seria completamente distinto.

Frente a estas candidaturas que no se atreven a presentarse con su verdadero rostro y que se empeñan por aparentar lo que 
Nada con los privilegiados

Seremos garantia para la mayoria no son, la Unidad Popular proclama que no tiene nada que ocultar, que puede, por tanto, llamar a las cosas por su nombre y que puede, asimismo, decir al país lo que es y lo que quiere hacer del gobierno y la forma en que lo concibe.

Hablando franca y honestamente, no somos una garantía para la minoría privilegiada. No somos una garantía para los intereses del capital imperialista que explota, intriga, corrompe y detiene el desarrollo de nuestro pais. No somos garantía para el latifundio ni para la oligarquía bancaria, ni para los potentados del capitalismo que ejercen en Chile el verdadero poder, no elegidos por cierto por el pueblo.

Con la misma franqueza decimos que el gobierno de la Unidad Popular, sí, será garantía para la abrumadora mayoria de la población, para el $90 \%$ o más de ella, compuesta de obreros, campesinos, empleados; profesionales y técnicos; estudiantes, maestros, intelectuales; pensionados y jubilados; artesanos, hombres con capacidad organizadora; la gran mayoria de los propietarios, productores, comerciantes, que no están unidos al estrecho círculo del poder capitalista, sino que lo sufren de muchas maneras.

El Gobierno del Pueblo trabajará con todos estos sectores para construir una economia basada en la planificación científica y democrática, donde cada cual tendrá su lugar de producción, de dignidad y de justa retribución de su esfuerzo. Solo asi habrá una verdadera disciplina social basada en el pueblo mismo. 


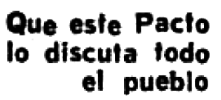

A enfrentar con decisión al enemigo
Los partidos y movimientos que integran la Unidad Popular han considerado indispensable hacer esta declaración y guiarse por ella en la campaña electoral, para marcar la diferencia entre su postulación y las otras que pretenden evitar el esclarecimento de los reales problemas del pais.

El movimiento popular estima que los problemas abordados en este pacto deben ser discutidos por todo el pueblo. por su decisiva incidencia en el carácter del futuro gobierno.

Sólo un Gobierno de Unidad Popular podrá abrir cauce a la capacidad creadora y al trabajo de millones de chilenos, para que sobre la base de la recuperación de las riqueras del pais, del cambio profundo de sus estructuras económicas y sociales y de la reforma de la institucionalidad podamos salir del estancamiento, de la carestía y la inflación, de la crisis que se propaga a todas las esferas $y$ construir una nueva sociedad.

Declaramos ante el pais el compromiso de ceñir nuestra acción a las normas y espiritu de este pacto, de actuar unidos y con la energia necesaria para llevar adelante las transformaciones y enfrentar con decisión a los enemigos de nuestra patria y de su pueblo.

LUIS CORVALAN L., Secretario General del Partido Comunista; ANICETO RODRIGUEZ. Secretario General del Partido Socialista: CARLOS MORALES A., Presidente del Partido Radical: ESTEBAN LEYTON, Secretario General del Partido Social Demócrata: JAIME GAZMURI, Secretario General de Movimiento Acción Popular Unitaria; ALFONSO DAVID LEBON, Presidente de la Acción Popular Independiente; LAUTARO OJEDA, Secretario.

Santiago, 26 de diciembre de 1969. 


\section{Acuerdo sobre conducción y estilo de la Campaña}

Sobre las ideas del Programa y proposiciones
Papel de la clase obrera y trabajadores
La campaña debe librarse sobre la base de las ideas y proposiciones concretas contenidas en el Programa.

Estas ideas y proposiciones tienen que constituir el tema central de un intenso y constante esclarecimiento ideológico que demuestre a los obreros, empleados, campesinos, estudiantes y sectores medios que sus intereses objetivos nada tienen en común con los de la Derecha y que nada pueden esperar del reformismo neocapitalista de la democracia cristiana.

La clase obrera y los trabajadores, por su experiencia y capacidad de lucha, deben tener un papel decisivo en el estilo y la tónica de la campaña, convirtiéndose en el motor que dinamice el proceso. Por su parte, las capas medias encontrarán en el Programa de la Unidad Popular, contempladas las reivindicaciones a sus problemas y por consiguiente, la motivación para incorporarse activamente al movimiento. 
Educar politicamente a las masas
Papel educador de la campaña
Lucha de clases

La campaña debe ser el medio para educar políticamente a las masas sobre la base del Programa, manteniéndolo abierto para enriquecerlo con nuevos aportes recogidos en el debate con las clases y sectores cuyos intereses están en él ampliamente contem. plados.

\section{Una intensa $y$ consciente movilización}

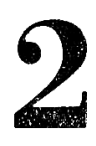

población.

Hay que desarrollar en el pueblo la conciencia de crear una sociedad socialista, la que no surge de la sola propaganda, sino mediante la lucha de las masas y un proceso de efectiva democratización. Esta conciencia se manifiesta en lucha tras objetivos que respondan a las necesidades, experiencias y aspiraciones de los trabajadores.

De ahí deriva el papel educador que debe revestir la campaña y que contribuirá a facilitar la labor y acción del futuro Gobierno Popular. Partiendo desde las necesidades concretas e inmediatas de las mayorías hay que imprimir a sus luchas un sentido más general hasta llegar a articularlas con los grandes objetivos del Programa. La conexión constante entre las necesidades inmediatas y las metas programáticas es algo que nunca debe descuidarse.

La lucha de clases, en cuanto corresponde a la realidad chilena, debe jugar un papel principal en la campaña.

Las fuerzas que conforman la Unidad Popular son integrantes de las grandes mayorías nacionales, surgen del seno mismo del 
Contra la demagogia reaccionaria

Desenmascarar

a Frei y su candidato

Las falacias de la reacción pueblo, $\mathbf{y}$, en consecuencia, no pueden ser ajenas a sus intereses. El pensamiento y la acción de los partidos y movimientos de la Unidad Popular estarán siempre presentes en todos los combates reivindicativos y enfrentamientos de los trabajadores con sus opresores, para encauzarlos por derroteros de victoria. No patrocinaremos una confrontación artificial, sino que la agudización de las contradicciones del sistema provocará un enfrentamiento cada vez mayor, que elevará las luchas de las masas a superiores niveles, planteándose final y necesariamente el pro. blema definitivo de la conquista del poder. En este proceso, como ya quedó expuesto, las fuerzas de la Unidad Popular toman decididamente la bandera de los trabajadores.

\section{candidatura de Tomic.}

La campaña debe dirigirse tanto contra la demagogia de la candidatura ultrarreaccionaria y. conservadora de Alessandri como contra la demagogia reformista y continuista de la

Hay que poner de relieve que representan lo mismo el gobierno democratacristiano de Frei y la candidatura democratacristiana de Tomic.

La denuncia del fracaso del gobierno democratacristiano de Frei es elemento importante de la campaña. También lo es la denuncia del fracaso del anterior yobierno de Alessandri.

La campaña evidenciará la falacia de la reacción al pregonar que las supuestas condiciones personales de su candidato son suficientes para solucionar los problemas del pais, en circunstancias que por este medio sólo tratan de ocultar los vicios y defectos de 
un sistema que ya ha hecho crisis y que por tanto debe ser reemplazado.

Han profitado 150 años

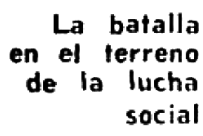

Plantear el Programa en todos los aspectos
No pueden apropiarse de los conceptos de orden, austeridad, honradez e inteligencia, quienes defienden un sistema de privilegios en contra de las grandes mayorías nacionales, en defensa de sus propios y mezquinos intereses económicos y que han profitado de la politica durante 150 años, cometiendo los mayores peculados. Orden, inteligencia, honradez y austeridad son conceptos que legitimamente corresponden al Gobierno Popular que implantaremos.

cretos.

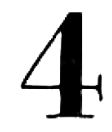

Contra las máquinas publicitarias y propagandisticas de las candidaturas reaccionarias el Movimento Popular dará la batalla en el terreno de la lucha social y de los problemas con-

Indiscutiblemente, la candidatura del pueblo representará, así, para la opinión pública la unica y verdadera solución popular para los problemas del hombre de trabajo y el progreso general del pais.

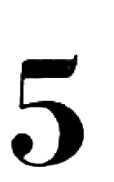

La campaña estará exenta de toda demagogia y reflejará en todos sus aspectos los planteamientos contenidos en el Programa. No hay que sembrar ilusiones, sino llevar al ánimo del pueblo el convencimento de su responsabilidad y de sus derechos y posibilidades de bienestar dentro de las estructuras de una nueva sociedad organizada, no en provecho de minorias privilegiadas, sino en beneficio de las grandes mayorias postergadas y de los sectores sociales que de una u otra manera son victimas del sistema. 

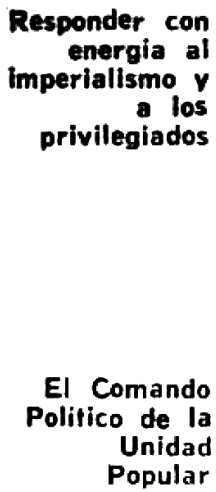

Organizar amplios comites

Expresiones germinales del poder Papular
Debe insistirse en la voluntad de aprovechar la dinámica del proceso renovador desencadenado con los cambios iniciales que contempla el Programa y reafirmar la voluntad inquebrantable de responder con la máxima energía a la resistencia del imperialismo y de los sectores internos privilegiados.

La dirección de la campaña es-

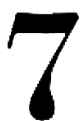
tará en manos de los Partidos, Movimientos y fuerzas integradas en la Unidad Popular.

a) Existirá un Comando Político a nivel nacional, en que estén representadas todas las colectividades que participan en el proceso unitario. Este Comando Político de alto nivel será el conductor, orientador y coordinador del movimiento y de la campaña.

b) En todo el territorio y con la densidad que se estime conveniente, deben organizarse amplios Comités de Unidad Popular, que sean los instrumentos regionales o locales para la realización de la campaña, sin perder de vista que las fuerzas sociales no pueden ser consideradas simples destinatarias, sino protagonistas centrales de la campaña y del proceso creador de la nueva sociedad.

Estos Comités deben ir convirtiéndose en cl curso de la campaña en expresiones germinales del poder popular que consquistaremos en 1970, comenzando aún antes de la victoria a concretar aspiraciones reivindica tivas de las masas y transformándose, una vez obtenidas, en factores dinamizadores y de dirección local de los procesos de cambios revolucionarios. 


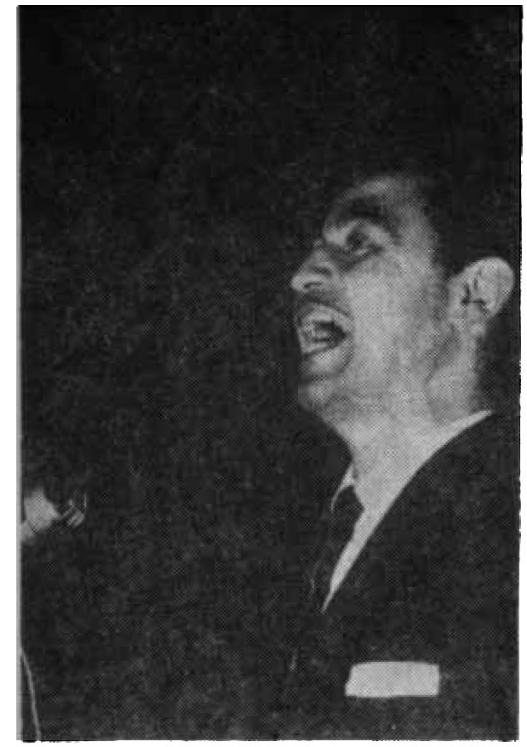

ESTEBAN LEYTON S.

Secretario General del

P.rtido Social Demócrata

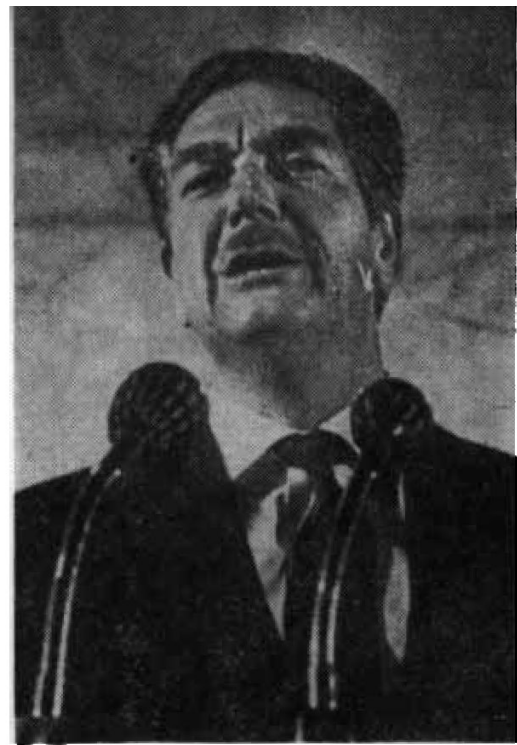

ALFONSO DAVID LEBON

Presidente de la

Acción Popular Independiente

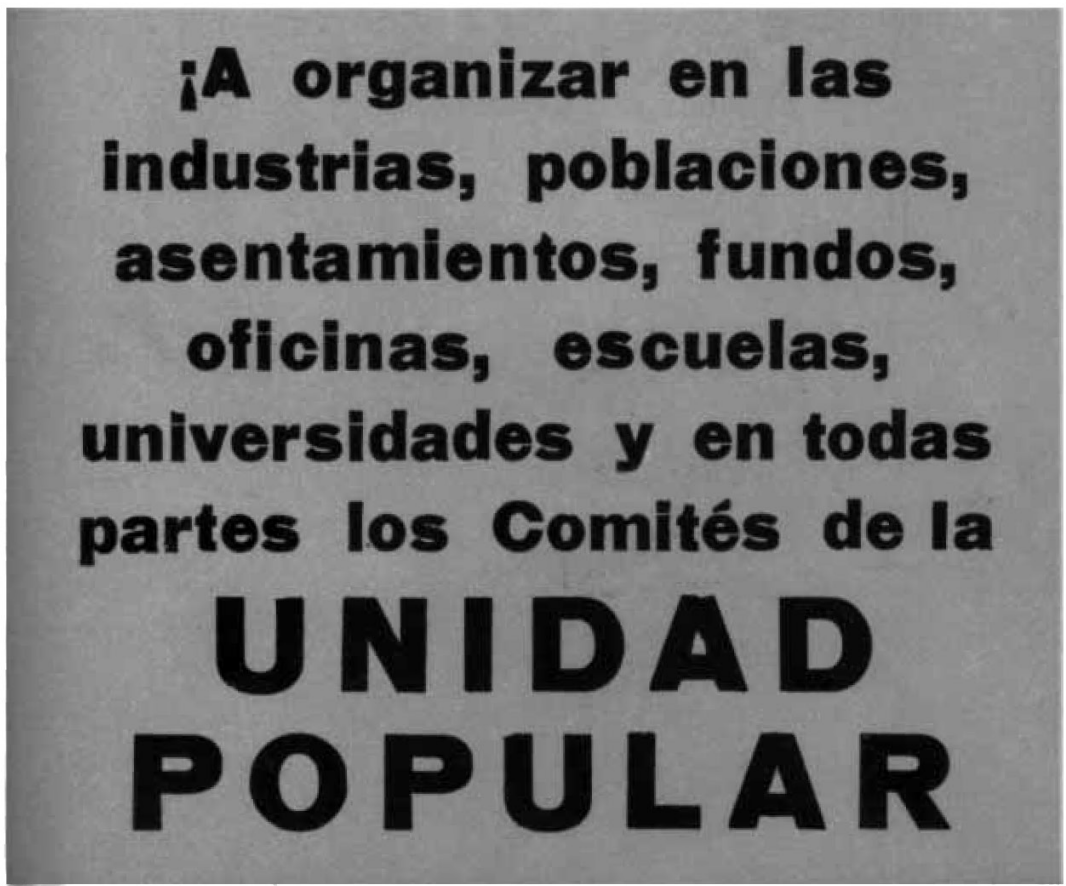

